\title{
Relationship Between Embitterment and Interpersonal Relation Among Patients with Diabetes
}

\author{
Sadia Irfan \\ Institute of Clinical Psychology (ICP), University of Management and Technology, Lahore \\ Maryam Rizvi \\ Institute of Clinical Psychology (ICP), University of Management and Technology, Lahore
}

\begin{abstract}
This study focuses on the relationship between embitterment and interpersonal relation among patients with diabetes. It was generally noticed that patients with diabetes would be more embittered if their interpersonal relation would not be healthy. Moreover, gender difference was also observed on both variables. In this study two scales were used for measuring embitterment and interpersonal relation among the diabetic patients. The result showed that there is negative relation between embitterment and interpersonal relation among diabetic patients. In the same way there is significant difference between males and female on embitterment and interpersonal relation among diabetic patients.
\end{abstract}

DOI: $10.7176 / \mathrm{JEP} / 11-1-04$

Publication date: January $31^{\text {st }} 2020$

\section{Embitterment}

Negative occasions of life can precipitate severe mental disorders. Reactive or adjustment disorders were listed by ICD 10 (WHO, 1992) and DSM-IV (APA, 2000). Numerous emotional reactions which are associated with threatening stressful life important crisis like anger, disappointment. Recently, Linden (2003) had pointed an emotion known as "embitterment" which is recurrently triggered and provoked by the negative consequences of deadlocks such as conflictual relationship at job, the death of loved one, ailment, and unemployment and so on. According to Lindon, embitterment can be defined as "persistent feelings of helplessness, being a loser, and revengeful." (Linden, 2003).

It is said to be a distinct mood which can share some emotional features of depression and anger but it can easily be differentiated from these emotions. Tuncay et al identified embitterment as an emotion characterized by feeling of let down with the strong urge to fight but not being able to attain that goal (Tuncay et al., 2008). It cannot be stopped by itself and constantly continued because this emotion is unpleasant and self-rising. It is similar to intrusive thoughts as in PTSD because embittered person recalls and remembers insulting and painful event and crisis over and over (Lopes \& Crespo, 2005). Few literatures have been found which have addressed embitterment (Hacker \& Stapf, 1998). Equivalently, Baures (1996) targeted embitterment and stressed upon the importance of letting go of the negative emotion to recover after the severe trauma. Weber (2003) had pointed bitterness revival as an element of memory and Znoj (2002) developed scale of embitterment when he was working with cancer patients. Linden and colleagues shared the psychopathological properties of embitterment such as it is a specific and special form of adjustment disorders (Linden, 2003; Linden et al., 2007). Those patients who experienced and act with elongated and perpetuated embitterment after negative events of life or crisis become vulnerable to develop psychological symptoms (Linden, 2003). Researches also have shown that feeling of mistrust or insult and in order to violating the values, are common features of such life events. Thus, one person can assume that embitterment and its severe consequences play vital role in everyday life as in the case of humiliation and feelings of injustice are said to be frequent life experiences in various life domains(Linden et al, 2008).

Interpersonal relationship is said to be a social link between two or more persons developed on emotions and feelings of the love or liking. Naturally, man attentive towards more companionship in relationship either with fellow same sex or opposite sex. Owie (2005) reported that man has more intrinsic desire to develop interpersonal relationship because it starts after newly born baby in the surrounding or within family and this birth bonding which invites one person for interpersonal relationship in the form of visual, tactile or auditory bonding between mother-child or father-child relationship (Owie, 2005). It is not the same to have a strong relationship with childbeing parents such as some may be natural while others become more social (Okere, 2010). Maxwell (2003) emphasized on the significance of making interpersonal relationship is as serious business between two people that can be yielded reward to those who committed to it. Additionally, Interpersonal relationship between two or more people, is also explained in terms of social association, connection or affiliation (Maxwell, 2003). Social association refers to a link with group of people with whom one place approval upon and voluntarily identify himself. Social connection is defined as a strong connection with people in which someone voluntarily decide to attach with them. Social affiliation helps to characterize and portray one person by manifestation of who is he and what he can achieve to the public (Maxwell, 2003). Various interpersonal relationship theories are based on the 
idea that people are looking for specific things in a connection with others (Walster \& Aronson, 1966). Uncertainty reductions theory refers to the idea when someone wants to be in relationship, her or she will try to learn about them to reduce or eliminate uncertainty between them. Social exchange theory is also called a relational theory such as exchange of goods is emotional and costs can be in form of poor communication or scarification of interests just to please other persons. On the other hand, rewards in relationship would be in form of, sharing mutual interests, being understood or companionship (Couch, 1990).

Studies have been argued that women as compared to men give attention to the underlying meanings about intimacy. On the other hand, men are more focused to between the line meaning about status and expectation of society as compare to women. (Tannen, 1990).

In this manner, women more emphasize and focus frequently on the comparability between their fellow mates to make those decisions which make every person happy not only themselves. In the case of men, they are supposed to assess relationships should be built and maintained on competition rather to cooperation and they also emphasized the dissimilarity between the man take those commitments relied on their personal requirements and wishes (Wood, 2010). WHO (2010) has also shared the prevalence of diabetes is that more than 220 million people are enduring from diabetes around the world and patients from developing countries are $80 \%$ and each year $5 \%$ of people died due to diabetes. It has been reported the prevalence of diabetes in Pakistan as 5,217,000 in 2000 and it is expected to be 13,853,000 in 2030 (WHO Eastern Mediterranean Region, 2010).

\subsubsection{Hypotheses}

1. There would be significant negative relationship between embitterment and interpersonal relationship among patients with diabetes.

2 . There would be significant difference between men and women on embitterment among patients with diabetes.

3. There would be significant difference between men and women on embitterment among patients with diabetes.

\subsection{Method}

\subsubsection{Research design and Participants}

To investigate the correlation among variables co-relational research design was used. Purposive sampling technique was used in this study to design our sample which is a method of non-probability sampling type. 200 diabetic patients with age range of participants was from 40 to 55 years (middle adulthood) with any type of diabetes were selected from public and private sector hospitals.

\subsubsection{Assessment protocols}

\subsubsection{Demographic Questionnaire}

A demographic questionnaire was used in which information was collected about the participant's age, gender, education, no. of children, family system, duration of disease, use of exercise.

\subsubsection{Posttraumatic Embitterment Disorder Scale}

PTED scale was developed in 2003 by Linden, as developing in response to a variety of causal stressful events, and these symptoms representing that these stressors have continuing effects in person's life. The Urdu version of PTED scale contained 26 items was used in the study and it was designed to access the characteristics of embitterment reactions to negative stressful life events. The Urdu version was translated by Jabeen and Subhan in 2016 and their reliability value was .93 .

\subsubsection{Relationship Scale}

An indigenous scale was developed which was valid and reliable and according to the cultural content. For this purpose, three step model: exploring phenomenology, expert validation and pilot study was used for scale development procedure. Relationship scale was consisted of 34 items which were further divided into three factors. The first factor is "Co-existence" in which 13 items of scale were included which showed the condition of living in harmony despite different ideologies. The second factor is called "Companionship" in which 13 items were included which reflected the theme about friendship. The third factor of relationship scale is "Accommodating" which comprised of 8 items. The response options were based on the 5 -point likert scale such as $0=$ never, $1=$ rarely, $2=$ sometime, $3=$ often, $4=$ very often.

\subsubsection{Procedure}

The ethical standards of research were considered as the participants given a brief description about the research and ensured that information kept confidential. Permission was also taken from the authorities of the concerned institutions. The data was collected through oral administration of questionnaire. Patients were asked to fill the questionnaire keeping in mind their present condition. In the end participants were thanked by researcher.

\subsubsection{Ethical Consideration}

The study was conducted by keeping in view the ethical considerations of research. Confidentiality of research participants was ensured. Informed consent was taken from participants. Participants were given information relating to purpose of research, the length of time required and procedure involved in research. Participants were 
debriefed at the end of study.

\subsection{Results}

In this section it is shown that current research highlights the results of main study. In this main study, three scales were used including Relationship scale (RS) for measuring interpersonal relationship of diabetic patients, Posttraumatic Embitterment Disorder Self- Rating Scale (PTED) to measure embitterment in patients with diabetes after disease.

The first hypothesis of research was that there is significant relationship between embitterment and interpersonal relation among diabetic patients. The correlation method was used to find out correlation among two variables such as interpersonal relationship and embitterment.

Table 1

Correlation, Mean and Standard Deviation of Factors of Relationship Scale and Posttraumatic Embitterment Scale $(N=200)$

\begin{tabular}{llllll}
\hline & RS & PTED & RSF1 & RSF2 & RSF3 \\
\hline RS & -- & -.07 & $.86^{* *}$ & $.84^{* *}$ & $.77^{* *}$ \\
PTED & & -- & $-.17^{*}$ & .11 & .03 \\
RSF1 & & & -- & $-.17^{*}$ & .11 \\
RSF2 & & & & -- & $.56^{* *}$ \\
RSF3 & & & & & -- \\
& 110.3 & 39.2 & 29.8 & 42.3 & 39.9 \\
$M$ & 15.8 & 14.4 & 11.8 & 6.7 & 6.9 \\
$S D$ &
\end{tabular}

Note. ${ }^{*} \mathrm{p}<.05,{ }^{* *} \mathrm{p}<0.01,{ }^{* * *} \mathrm{p}<0.001 ; \mathrm{RS}=$ Relationship Scale, PTED $=$ Posttraumatic Embitterment Scale, RSF1= Relationship Scale Factor 1, RSF2=Relationship Scale Factor 2, RSF3= Relationship Scale factor 3, $M=$ Mean, $S D=$ Standard Deviation.

Table 1 shows that the correlation of the factors of Relationship Scale (RS) and Posttraumatic Embitterment Scale (PTED). The correlation analysis revealed the negative correlation between factors of Relationship Scale of patients with diabetes.

The second hypothesis of the present study was that there is significant difference between males and females on embitterment among the diabetic patients. Independent sample t-test was used for this analysis.

Table 2

Mean and Standard Deviation and $t$-values of Embitterment with Gender $(N=200)$

\begin{tabular}{|c|c|c|c|c|c|c|c|}
\hline & & & $95 \% \mathrm{Cl}$ & & & & \\
\hline Gender & $M$ & $S D$ & $L L \quad U L$ & $d f$ & $t$ & p-value & Cohen'd \\
\hline Men & 46 & 13 & $12.0 \quad 18.8$ & 198 & 8.91 & .000 & 1.24 \\
\hline
\end{tabular}

Note. $\mathrm{M}=$ mean, $\mathrm{SD}=$ standard deviation, $\mathrm{df}=198, \mathrm{Cl}=$ confidence interval, $\mathrm{LL}=$ lower limit, $\mathrm{UL}=$ upper limit

Table 2 showed the significant gender difference exist between men and women on embitterment. Further men have more embitterment as compared to women.

The third hypothesis of the present study was that there is significant difference between males and females on interpersonal relation among the diabetic patients. Independent sample t-test was used for this analysis.

Table 3

Comparison of Mean on factor Co-existence (Relation scale) Men and Women by Independent Samples t-test $(N=200)$

\begin{tabular}{lcccccccc} 
Gender & $M$ & $S D$ & $L L$ & $\frac{95 \% C l}{U L}$ & $d f$ & $t$ & $p$-value & Cohen'd \\
\hline Men & 41 & 6 & & & & & & \\
& & & -4.3 & -.67 & 198 & -2.69 & .008 & 0.30
\end{tabular}

Note. $\mathrm{M}=$ mean, $\mathrm{SD}=$ standard deviation, $\mathrm{df}=198, \mathrm{Cl}=$ confidence interval, $\mathrm{LL}=$ lower limit, $\mathrm{UL}=$ upper limit

Table 3 showed that there is significant difference exist between men and women on co-existence (interpersonal relation scale). Further women have more mental co-existence (relation scale) as compared to men.

\section{Discussion}

The present research consists of three factors such as interpersonal relationship and embitterment in patients with diabetes. Nowadays, it can be easily seen that diabetes is seemed to be common disease worldwide. Patients with diabetes bear many psychological problems which affect their lives. This research explored the experiences of patients with diabetes in Pakistan which uncover these three abovementioned dimensions in them. Diabetes is the 
name of disturbance in pancreas in which it does not secret enough insulin or the body has problem in using insulin (Vinicor, 2004).

According to WHO and International Diabetes Federation (2010), type II diabetes is said to be frequently reported than type I diabetes. In this research, it was asked from the participants about type of diabetes which they are suffering from but due to lack of awareness they were unable to share about the type of diabetes. They didn't know about the types of diabetes which they had.

In the main study, it was hypothesized that there would be negative relationship between interpersonal relationship and embitterment in patients with diabetes which is also proved by result that there is negative significant correlation between embitterment and interpersonal relationship. Few studies have been done on interpersonal relationship but there was not any research which could explore the relationship of embitterment. Thus, it is assumed that all individuals through the socialization process and social interaction develop sense of self and these interactions with others serve to create and foster interpersonal relationships with others (Articlesng, 2013). It also helps them to curtail their bitterness by catharsis or share their emotions, feelings, thoughts.

It was also resulted that men had more embitterment as compare to women and there was significant difference was found between them. Kurt and Donald (2010) conducted research in which gender differences was assessed on embitterment due to infidelity of the spouse and it was summarized that in infidelity victims PTED is diagnosed in nearly $90 \%$ of the husbands and only $40 \%$ of the wives were rated as experiencing the emotional component of embitterment (Kurt \& Donald. 2010). Whereas in our culture, men are considered the breadwinners and take pride in providing for their families. They had great responsibilities of their families on them which make them inexpressive to some extent and when they reach at middle age and also suffering from diabetes that also make them embittered because at that age and stage men use to retired from their jobs or most of men become dependent on their children which also lead them to be embittered with passage of time. Furthermore, when data was being collected from them, participants were so amazed when they got to know how embitterment is linked with their disease, they admitted that they feel themselves bitter in many steps of their lives and some of the participants reported their thoughts that "their bitterness is merely due to external pressures and stressors in their lives". This can also be validated from Erikson's theory of psychosocial development in which Generativity and Stagnation is the seventh phase of his theory which occurred during middle adulthood between periods of around 40 and 65 years. Generativity refers to making your blemish on the world through looking after others as well as creating and accomplishment things that make the world better place. On the other hand, Stagnation refers to the failure to find a way to contribute. These people may feel disengaged or uninvolved with their community and with society all in all. During this time, adults endeavor to make or sustain things that will outlast them often by parenting children or contributing to positive changes that advantage to other people. Contributing to society and doing things to benefit future generations are important requirements at the generativity versus stagnation phase of development (Erikson, 1993).

\section{Reference}

American Psychiatric Association. (2000). Diagnostic and statistical manual of mental disorders. Washington, DC: Author.

Articlesing, (2013). Self-esteem in interpersonal relationship- its influence among students. Retrieved from http://articlesng.com/selfesteem-interpersonal-relationship-influence-students.

Baures, M. M. (1996). Letting go bitterness and hate. Journal of Humanistic Psychology, 36, 75-90.

Couch, D. (1990). Towards a theory of social processes. Symbolic Interactionism, 15, 34-117.

Erikson, E. H. (1993). Childhood and Society. New York: Norton.

Hacker, H. \& Stapf, K. H. (1998). Dorsch Psychologists Worterbuch. Bern: Hans Huber.

International Diabetes Federation. (2010). Types of diabetes. Retrieved from http://www.idf.org/typesdiabetes.

Kurt, H., \& Donald, H. (2010). Risikofaktoren für Untreue - Warum Partner fremdgehen. Zeitschrift fur Klinische Psychologie und Psychotherapie, 39(3), 189-199. DOI: 10.1026/1616-3443/a000037.

Linden, M. (2003). Posttraumatic Embitterment Disorder Psychotherapy and Psychosomatics, 72 (4), 195-202 DOI: $10.1159 / 000070783$.

Linden, M., Rotter, M., Baumann, K., \& Lieberei, B. (2007). The Post-Traumatic Embitterment (PTED). Bern: Hogrefe \& Huber.

Linden, M., Baumann, K., Rotter, M., \& Schippan, B. (2008). Diagnostic criteria and the standardized diagnostic interview for posttraumatic embitterment disorder (PTED). International Journal of Psychiatry in Clinical Practice, 12, 93-96.

Lopes, L., \& Crespo. K. (2005). Factors associated with the positive impact of caring for elderly and dependent relatives. Archives of Gerontology and Geriatrics, 41(1), 81-94.

Maxwell, J. (2003). Handbook of mixed methods in social and behavioral research. Thousand Oaks, CA: Sage.

Okere, G. (2010). Level of health education instruction among secondary schools in Imo State, Nigeria. Retrieved from http/www/smart marriages. 
Owie, I. (2005). Health Education: Curriculum \& Instruction. Benin: Minder press.

Tannen, D. (1990). You just don't understand: Women and men in conversation. New York: Ballantine Books.

Tuncay, T., Musabak, I., Gok, D. E., \& Kutlu, M. (2008). The relationship between anxiety, coping strategties and characteristics of patients with diabetes. Health Quality Life Outcomes, 6(1), 79-89.

Vinicor, F. (2004). Diabetes a to z (5th ed). New Delhi: American Diabetes Association, Inc.

Walster, E., Aronson, V., Abrahams, D., \& Rottman, L. (1966). The importance of Physical attractiveness in dating behavior. Journal of personality and social psychology, 4, 508-575.

Weber, F. (2003). Development of neural processes mediating rhyme judgments: phonological and orthographic interactions. Journal of development Psychobiology, 43(2), 128-145.

Wood, J. (2010). Gendered lives: Communication, gender, and culture (8th Edition). Belmont, CA: Wadsworth Publishing.

World Health Organization. (1992). The ICD-10 classification of mental and behavioral disorders: Clinical descriptions and diagnostic guidelines. Geneva: Author.

Znoj, H. (2002). Perceived responsibility for change as an outcome predictor in cognitive behavioral group therapy. British journal of clinical psychology, 47, 281-293. 